\title{
Proposta de um Atlas Bilingue Português/Kimbundu de Anatomia
}

\section{Proposal for a Bilingual Portuguese/Kimbundu Atlas of Anatomy}

DOI: $10.54019 / \operatorname{sesv} 3 n 1-014$

Recebimento dos originais: 05/07/2021

Aceitação para publicação: 20/08/2021

\author{
Ana Pita Grós Martins da Silva \\ Professora Associada da Faculdade de Humanidades da Universidade \\ Agostinho Neto \\ E-mail: anpigromasil@gmail.com
}

\section{RESUMO}

Este trabalho tem como temática central Proposta de um Atlas Bilingue Português/Kimbundu de Anatomia. Trata-se, pois, de uma investigação interdisciplinar, envolvendo as áreas de Linguística, Medicina e Informática.

A pesquisa centra-se na perspectiva de contribuir para a promoção e diversificação de teorias e métodos de ensino articulados à Didáctica do Ensino do Português Língua Segunda.

Preocupamo-nos com questões relacionadas com a dualidade do signo: significado-significante, o que implica o estudo de questões conceptuais, nocionais, referenciais e semânticas, no âmbito da problemática da estruturação do léxico.

Palavras-chave: Atlas, Anatomia, Ensino, Bilingue e Língua Segunda.

\section{ABSTRACT}

The central theme of this work is the Proposal of a Bilingual Portuguese/Kimbundu Atlas of Anatomy. It is, therefore, an interdisciplinary research, involving the areas of Linguistics, Medicine and Informatics.

The research is focused on contributing to the promotion and diversification of theories and teaching methods articulated to the Didactics of Teaching Portuguese as a Second Language.

We are concerned with issues related to the duality of the sign: signifier-meaning, which implies the study of conceptual, notional, referential and semantic issues, within the scope of the problematic of lexicon structuring.

Keywords: Atlas, Anatomy, Teaching, Bilingual, Second Language.

\section{INTRODUÇÃO}

A aprendizagem das Línguas Nacionais constitui um imperativo de Angolanidade porque, para além de possibilitar o contacto entre os vários actores integrantes de uma mesma comunidade, permite, de igual modo, a identificação de cada povo com todos os demais angolanos em direcção à Nação única, como 
resultado do todo, consolidando, desta forma, o imperativo constitucional de unidade estadual e do pluralismo ideológico e cultural.

Ainda hoje, o ensino é organizado de modo a privilegiar o estudo de conceitos, linguagem e metodologias, tornando a aprendizagem pouco eficiente para a interpretação e intervenção na realidade. Assim sendo, a Anatomia constitui uma oportunidade de estímulo para o ensino- aprendizagem.

O processo de ensino/aprendizagem torna-se mais eficaz quando se associa a teoria à prática. Disciplinas como a Anatomia estão relacionadas ao quotidiano do aluno. Alguns conteúdos são difíceis de serem visualizados em aulas expositivas, necessitando de práticas e de recursos didácticos para o aluno visualizar e construir, com autonomia, o saber científico.

Existem diversas estratégias didácticas, desde a forma tradicional nas escolas, passando pelo quadro-negro e giz, até às mais modernas, utilizando computadores. Pode-se conceituar o ensino como um processo de facilitação ou condução, com o objectivo de que o aluno aprenda.

O processo de ensino-aprendizagem caracteriza-se pela combinação de actividades do aluno dirigidas pelo professor, há necessidade de acreditar no aluno, na sua capacidade de aprender, descobrir, criar soluções, desafiar, enfrentar, propor, escolher e assumir as consequências da sua escolha.

Este Atlas pode ser utilizado tanto pelo professor durante as aulas teóricoexpositivas, fazendo, assim, a interacção entre elas, quanto pelos alunos como um recurso de estudo, em que possam ser estimulados a participar de forma mais activa na construção do conhecimento.

O estudo bilingue da Anatomia é imprescindível para o conhecimento e compreensão do corpo humano como um todo, quando a língua materna dos alunos é diferente do idioma de ensino. Assim, torna-se eficaz a interacção e imersão do educando em todas as estruturas e características de cada um dos órgãos, ou partes, como meio essencial para promover a vida, prevenir, cuidar e curar os males enquanto técnica, arte e ciência.

\section{OBJECTIVOS}

- Contribuir para a Didáctica do ensino/aprendizagem do Português Língua Segunda no Ensino Geral; 
- Facilitar a comparação das imagens obtidas por um esquema bilingue que coincidem com as estruturas reais;

- Promover a inserção das Línguas Nacionais no Ensino Geral, facilitando a sua utilização como língua de pensar, querer e agir como língua de comunicação e de cultura.

\section{METODOLOGIA}

Com a necessidade de minimizar as dificuldades de comunicação, que os professores e alunos enfrentam, sentimos a necessidade de propor um Atlas Bilingue Português/Kimbundu, de Anatomia, capaz de motivar e valorizar os esforços dos alunos, promovendo um melhor domínio do Português Língua Segunda, dos conteúdos disciplinares teóricos e práticos no Ensino Geral.

Para a execução desta nossa pretensão, recolhemos as gravuras do Atlas de Anatomia, em Português, do corpo humano, do esqueleto, assim como dos aparelhos digestivo, respiratório, urinário, reprodutor feminino e reprodutor masculino.

Os dados foram organizados, catalogados e traduzidos para a Língua Nacional Kimbundu a fim de se tornarem uma fonte de consulta importante para o estudo.

Como complemento, fizemos uma consulta bibliográfica que contribuiu para a justificação dos nossos argumentos sobre o tema em análise. O nosso estudo não foi exaustivo porque constitui uma primeira abordagem.

A elaboração de um recurso didáctico nem sempre é fácil, mas com motivação, empenho e bom senso, as dificuldades podem ser superadas.

\section{CORPUS}

O nosso corpus bilingue de referência no domínio da Anatomia é constituído por vários subcorpus: documental, lexicográfico, textual e oral que serviu de base à selecção dos termos em Português e respectivos equivalentes em Kimbundu.

\subsection{Características da Língua Kimbundu}

O Kimbundu é uma Língua Bantu como tantas outras já mencionadas no trabalho. Segundo Théophile Obenga (1985), essas línguas têm características 
comuns; passamos a apresentar as mais significativas:

- A prefixação dos morfemas flexionais: estas línguas apresentam um sistema de classes, caracterizado por prefixos nominais, onde cada classe tem um número.

- $\quad$ Estes morfemas são classificados em função dos seus prefixos, onde os números ímpares representam o singular e os números pares o plural, (considerada reflexão regular correspondendo as classes de 1 a 10).

- A utilização de tons no interior de um mesmo significante permite opor o significado de duas unidades lexicais, na maioria dessas línguas. Assim, o tom contribui para a oposição de sentidos das unidades lexicais, mas num contexto fonético semelhante.

- O sistema vocálico é simétrico: comporta uma vogal central/a/, duas vogais anteriores /i/, /e/ e duas vogais posteriores /u/, /o/.

- O sistema consonântico comporta pré-nasais, como consoantes orais precedidas de consoantes nasais, formando grupos indivisíveis.

\subsection{Alfabeto da Língua Kimbundu}

Vários investigadores concluíram que a Língua Kimbundu comporta os seguintes fonemas:

Cinco vogais (a, e, i, o, u), sendo: uma vogal central /a/, duas vogais anteriores /e, i/ e um número idêntico de vogais posteriores /o, u/.

Não apresenta nenhuma vogal nasal, isto é, as vogais que seguem uma consoante pré-nasal realizam-se nasalizadas.

Duas semi-vogais: /y/, /w/

Dezasseis consoantes: /b/, /d/, /f/, /g/, /h/, /j/, /l/, /m/, /n/, /p/, /r/, /s/, /t/, /v/, $\mid \mathbf{x} /, \mathbf{z} /$.

Uma particularidade do Kimbundu é o facto de todas as palavras terminarem em vogal.

\section{TERMINOLOGIA}

A Terminologia, hoje, é considerada uma disciplina autónoma que se baseia em dois alicerces: 1) um objecto próprio: o conceito e o termo; 2) um quadro conceptual bem definido com uma terminologia específica.

A Norma ISO (1087) define conceito como:

"unité de connaissance créée par une combinaison unique de caracteres. NOTE Les concepts ne sont pas nécessairement liés à des langues particulières. Ils sont cependant soumis à l'influence du contexte socioculturel qui conduit souvent à des catégorisations diferentes". 
No plano da língua, o conceito é designado por um termo:

"désignation verbale d'un concept general dans un domaine spécifique. NOTE Un terme peut être constitué de symboles et peut avoir des variantes", Norma ISO 1087.

As línguas de especialidade e as terminologias que as caracterizam são matérias importantes para a carreira do ensino actual, pois, os termos científicos e técnicos definidos de maneira incorrecta, ou a incoerência no uso dos mesmos, origina problemas didácticos tanto a docentes, como a discentes, como aos profissionais que as utilizam.

No século XX, com o surgimento de escolas clássicas de Viena, de Praga e da Rússia, com características similares, que a Terminologia se desenvolveu de forma expressiva.

Foi Wüster quem desenvolveu a Teoria Geral da Terminologia (TGT). O autor não era linguista, mas sim um engenheiro que teve necessidade de formular uma teoria que possibilitasse uma comunicação eficiente e sem ambiguidade entre profissionais de um mesmo domínio; consequentemente, a sua abordagem defendia a intervenção na composição das terminologias, a fim de obter uma estandartização (cf. CABRÉ, 2006: 19).

A preocupação com essas questões levou Wüster, fundador da escola de Viena, a criar o Comité 37 da International Organization for Standardization (ISO) com o intuito de regulamentar a prática terminológica (cf. CABRÉ, 2006: 162). A variação do significado, numa óptica linguística, não tem lugar na teoria do mesmo autor, ou seja, na sua abordagem, os termos expressam conceitos, entendidos como unidades de conhecimento únicas e invariáveis.

A ISO destaca a necessidade de harmonizar o conhecimento especializado; o papel da organização não-governamental tem como objectivo facilitar a coordenação e unificação internacional de normas industriais, que regulem e promovam a actividade terminológica. O sistema de estandardização da ISO parte das necessidades internacionais de harmonização em termos económicos, políticos e sociais a ser implementado em cada país.

Para esta instituição, a Terminologia é definida segundo três acepções:

(i) «ensemble des désignations à une langue de spécialité; 
(ii) science étudiant la structure, la formation, le développement, l'usage et la gestion des terminologies dans différents domaines,

(iii) terminologie structurée de façon systématique selon des règles de dénomination pré-établies» (ISO/FDIS-1087-1, 2000, p. 10).

Nesta definição dá-se conta das polissemias do termo "terminologia", ou seja, conjunto de termos de uma determinada área do conhecimento, uma ciência, ou ainda uma terminologia estruturada, segundo princípios utilizados para descrever um domínio de especialidade.

\subsection{Terminologia, Lexicologia e Lexicografia}

A Terminologia e a Lexicologia são duas disciplinas que guardam entre si como factor de aproximação a descrição de unidades lexicais, embora marcadas por uma interpenetração entre subsistemas da língua geral, por transferências semânticas que ocorrem da língua de especialidade para a língua geral e viceversa.

O conjunto das unidades lexicais de uma língua é composto por dois subconjuntos: o da língua corrente e o das línguas de especialidade. Ou seja os trabalhos lexicológicos podem tomar como objecto de estudo todas as unidades lexicais da língua geral, mas os trabalhos terminológicos limitam-se ao estudo do termo, forma linguística com características próprias.

A Lexicologia tem por objecto o léxico de um modo geral, enquanto a Terminologia centra-se na unidade lexical especializada e nos conceitos que caracterizam as áreas de conhecimento. As suas bases metodológicas podem ser aplicadas no ensino das línguas materna e estrangeira, na tradução, na elaboração de dicionários especializados, no ensino das disciplinas técnicas e científicas, na documentação, no jornalismo científico, nas ciências sociais, na transferência de saber técnico e científico, na produção industrial e nas políticas linguísticas.

Assim, a Lexicologia tem como objecto as unidades lexicais da língua corrente; por isso, não se confunde com a Terminologia que tem como objecto as unidades lexicais especializadas ou termos relativos a domínios de especialidade. São, hoje, duas disciplinas com quadros conceptuais bem delimitados e terminologias específicas. 
A Lexicologia ocupa-se dos problemas teóricos que estão na base do estudo científico do léxico.

Segundo Isquerdo \& Oliveira (2001, p. 27), a Terminologia tem como objecto de estudo os termos, as unidades lexicais especializadas das línguas de especialidade, relativos aos conceitos de diferentes áreas de conhecimento.

A Terminologia distingue-se da Lexicologia no modo como encara o seu objecto. Enquanto a Lexicologia é essencialmente descritiva, a Terminologia é descritiva e normativa, pois ambas dão um tratamento diferente à sinonímia, à homonímia e à neologia. Enquanto na Lexicologia a sinonímia é equivalente de enriquecimento da língua, na Terminologia deve ser controlada de modo a manter a clareza das línguas científicas e técnicas.

Os métodos da Terminologia e da Lexicologia distinguem-se pelo percurso. A metodologia lexicológica segue um percurso semasiológico, no sentido em que toma como ponto de partida uma forma linguística para explorar os seus valores semânticos; já a metodologia terminológica é de carácter onomasiológico, ou seja, consiste em procurar uma denominação que represente um conceito.

Acontece que, às vezes, o terminólogo é levado a escolher ou a fixar um trabalho de normalização ou mesmo criar uma denominação para um conceito novo. Quanto aos seus métodos de recolha de termos, a Terminologia deve determinar primeiro se o mesmo pertence à área do conhecimento que se pretende estudar, ao contrário da Lexicologia que faz uma análise semântica da unidade lexical. Assim, podemos afirmar que a Terminologia tem como objectivo reunir os resultados da investigação terminológica para os pôr à disposição dos utentes de maneira sistemática, elaborando dicionários terminológicos, diferentes dos da língua corrente.

Uma das características da Terminologia, como ciência, é o rigor que imprime nos seus trabalhos metodológicos, presentes não só em grupos nacionais como internacionais. Para uns, esses trabalhos estão ligados à tradução, como é o caso das comunidades europeias, para outros, servem para a difusão de uma língua e a preservação da sua integridade (como é o nosso caso Angolano), e para outros, esses trabalhos seguem objectivos múltiplos e paralelos.

Esta especificidade de objectivos levou o Comité Técnico no 7 da ISO a elaborar e adoptar normas internacionais de Terminologia, apoiando-se em 
critérios rigorosos.

Nas perspectivas tradicionais, termo e definição possuem um valor conferido pela univocidade que caracteriza o léxico especializado. No entanto, sublinharemos muito mais a condição de produção do discurso especializado, pois é nesse contexto social de produção discursiva que o termo e a definição ganham contornos de especialidade, ganhando significação por quem os usa. Além do mais, o termo e a definição, como duas faces da mesma moeda, devem integrar o quadro que constitui o objecto de investigação terminológica.

Um dos princípios básicos da língua e postulado pela própria Sociolinguística é o fenómeno da variação, inerente a toda a manifestação linguística. Assim, a Socioterminologia, considerando os princípios da Sociolinguística, refuta os moldes tradicionais impostos pelos estudos clássicos da Terminologia. Essa nova maneira de estudar o termo tem em conta a variação e a condição de produção das terminologias no contexto sociocultural.

\section{LÍNGUA DE ESPECIALIDADE, LÍNGUA PARA FINS ESPECÍFICOS E TERMINODIDÁCTICA}

A aquisição de conhecimentos técnicos, científicos e profissionais, assim como, dos meios linguísticos que permitem a comunicação passam, obrigatoriamente, pelo ensino/aprendizagem das línguas de especialidade. $O$ aluno só atingirá um determinado nível (elementar, independente, competente, avançado, segundo a classificação do Quadro Europeu de Referência para as Línguas) numa língua de especialidade, considerando as competências linguísticas já adquiridas na sua língua materna ou na língua que está em processo de aprendizagem.

Para o desenvolvimento do ensino das línguas de especialidade (designadas de línguas para fins específicos, numa perspectiva de didáctica) e respectiva terminologia de um determinado domínio, é necessário uma organização linguística e terminológica, que passa, num primeiro plano, pelo incentivo à utilização de programas de investigação e de produção de instrumentos de divulgação do conhecimento científico e técnico.

Defendemos que, as empresas podem encarar melhor as exigências do mercado e contribuir para o desenvolvimento económico e de forma auxiliar, para 
a valorização da língua, com terminologias consistentes estabelecidas segundo critérios que se regem pelas metodologias utilizadas em Terminologia que resultam numa organização estruturada e hierarquizada da esfera do conhecimento.

Costa defende que as «...terminologias são um instrumento fundamental de ajuda à preservação de uma língua...” (2005, p. 5), ou seja, na medida em que permite uma melhor difusão e consolidação de uma Língua Nacional, determina a produção de produtos de divulgação dessas terminologias e das línguas de especialidades.

Ao abordarmos a problemática da identidade linguística e cultural, perante a diversidade linguística existente em Angola, traçamos três caminhos que pretendemos interligar no desenvolvimento desta investigação, como:

(i) O estudo da constituição e da harmonização de terminologias, estudando os termos, os conceitos e a relação entre eles;

(ii) A aprendizagem do léxico de especialidade, considerando o seu funcionamento linguístico;

(iii) A construção de produtos terminológicos e didácticos, com recurso às novas tecnologias que sirvam os interesses dos utilizadores.

O desenvolvimento económico do País passa também por uma política de preservação e valorização das Línguas Maternas, podendo essa preservação ser feita através do aumento da investigação e do ensino dessas línguas. O nosso objectivo é a criação de recursos terminológicos possíveis de serem utilizados com um carácter didáctico, dando assim um contributo para o ensino das nossas Línguas Angolanas de origem Africana.

Neste contexto, recorremos ao conceito de "Terminodidáctica" que surgiu relacionado com 0 «...ensino da terminologia, em língua materna ou em língua estrangeira a vários níveis (do sistema escolar, por exemplo) e a diferentes tipos de públicos (em sistemas escolares e não-escolares)» Lino (1991, p. 2).

A Terminodidáctica surge, assim, como uma vertente da Terminologia que se preocupa com o ensino da terminologia em contextos diversos. Para a concepção e para o desenvolvimento de recursos terminológicos que possam ser utilizados em situação de sala de aula, é necessário pensar na vertente informatizada.

A informática é a parte integrante da metodologia em Terminologia, Sager 
refere:

«...terminology collection and processing is a semiautomatic process, constantly responding to innovations borrowed from information technology, information science and computational linguistics...» (1990, p. 5).

É um recurso de considerável importância, quer para o desenvolvimento da investigação, quer para o ensino das línguas. A este respeito Piri salienta:

« L'apprentissage des langues est aussi facilité par le progrès rapide des technologies de l'information et de la communication (...) et les médias (... favorisent tous le développement des compétences linguistiques» (2002, p. 14).

A Didáctica das Línguas para fins específicos remete-nos para o conjunto dos métodos, hipóteses e princípios necessários à aprendizagem das línguas, mais especificamente das línguas de especialidade, na medida em que é considerada

"[...] como a articulação de vários saberes, visando criar condições favoráveis à aprendizagem de determinada matéria; e sendo constituída por um conjunto de técnicas que préestabelecerem, ao ensino, princípios e métodos que se destinam a criar condições favoráveis para que o aluno possa de maneira eficaz tirar partido do ensino/aprendizagem [...]" (Lamas, 2000, p. 126).

Desta forma, elaboram-se estratégias que passam pelo recurso aos meios informáticos, que permitem um melhor acesso ao conhecimento especializado, de acordo com as metodologias próprias da ciência terminológica.

Desenvolvemos a nossa investigação, numa perspectiva terminológica, tendo em conta as lacunas existentes em termos de investigação em Terminologia para o ensino do Kimbundu. Partimos da análise e organização terminológica para propor um produto que possa ser utilizado como um recurso didáctico na aprendizagem de uma língua de especialidade. Para tal, é necessário definir objectivos e direccionar o produto para um público e um contexto pedagógico específico.

Assim, a interactividade entre o profissional e os conteúdos, possibilitada pela tecnologia digital, proporciona que a aprendizagem possa ser a "qualquer hora" e em "qualquer lugar", permitindo que os utilizadores acedam a ambientes 
de aprendizagem virtuais, independentemente da localização geográfica e do fuso horário.

\section{CONCLUSÃO}

A língua aprende-se por necessidade comunicativa, e não por imposição de espécie alguma. É falso pensar, em termos científicos e pedagógicos, que uma determinada língua pode ser recuperada na escola. Sabemos que foi nas universidades europeias que o latim morreu.

A ciência hoje é objecto de larga divulgação, tanto que houve um tempo em que se postulava que o conteúdo das línguas especializadas era de uso restrito aos profissionais da área; actualmente, a ciência e a tecnologia tornaram-se objectos de notícia e nessa altura, de interesse do público não-especializado.

A aquisição dos saberes técnicos, científicos e profissionais, assim como, dos meios linguísticos que permitem a sua expressão e comunicação, passa pelo ensino/aprendizagem das línguas de especialidade, quer se trate do ensino de línguas segundas ou do ensino das línguas maternas, num contexto de formação.

Quando falamos de inserção das línguas nacionais, no sistema educativo, não pretendemos que as crianças sejam obrigadas a aprender as línguas que não desejam aprender. Pelo contrário, pretendemos que os direitos linguísticos dos Angolanos sejam respeitados, observados, e que as nossas línguas tenham material didáctico, à semelhança de outras línguas do mundo.

A funcionalidade operada pelo léxico especializado na transmissão de conhecimentos, na transferência de aparatos tecnológicos, bem como, nas relações contratuais faz com que, cada vez mais, a terminologia assuma relevância na e para a sociedade actual, cujos paradigmas de desenvolvimento estão intimamente relacionados ao processo de economia globalizada e ao acelerado desenvolvimento científico e tecnológico.

Não podemos, no entanto, ignorar a dificuldade que existe em proteger a identidade linguística, no contexto de globalização em que nos inserimos. A globalização da economia, que se verifica pelos acordos comerciais internacionais, dá prioridade absoluta aos acordos económicos, ligados à utilização de uma língua dominante, ameaçando a diversidade linguística.

No entanto, é o poder do mercado que impede, por vezes, que a 
diversidade linguística seja assegurada em todas as circunstâncias da vida social, política e económica do cidadão. Este facto faz com que uma língua estrangeira tenha mais condições para ser utilizada nas interacções do que uma língua local.

Assim, em primeiro lugar, há que fazer um levantamento das diferentes necessidades existentes, relativas aos estudos das línguas. A aprendizagem das línguas deve ser uma aprendizagem e um contributo à compreensão plural e à tolerância e solidariedade no quadro de novas aproximações da interculturalidade e da multiculturalidade.

É necessária a elaboração de produtos informáticos, de ensino/aprendizagem em língua nacional, que acompanhem a evolução das novas tecnologias colmatando as lacunas identificadas ao nível científico, profissional e académico.

A necessidade de contar com obras de referência plurilingues na busca quer de conceitos, quer de denominações terminológicas atinge uma extensa gama de profissionais envolvidos com as linguagens técnicas. Entre eles, destacam-se os tradutores, intérpretes, documentalistas, redactores técnicos, lexicógrafos e terminógrafos, estudantes universitários, bem como, profissionais considerados como usuários indirectos da terminologia.

A sociedade actual sofre o impacto da acelerada produção do conhecimento, traduzido pelas mais variadas inovações tecnológicas que afectam o seu quotidiano. Vive-se um processo de alfabetização técnico-científica, o que determina a ampliação de contactos com as terminologias.

A terminologia é sem dúvida um instrumento privilegiado da promoção das línguas e a investigação terminológica é igualmente um instrumento privilegiado para o desenvolvimento das línguas de especialidade.

A existência e a circulação de terminologias em distintos cenários comunicativos são testemunhos de que essas cumprem, a dupla função de fixar o conhecimento técnico-científico e de promover a sua transferência de modo pontual; deste modo delineia-se também o papel social das terminologias no âmbito da comunicação humana. A esse papel está também associada a ideia de normalização ou harmonização.

A tentativa de estabelecer uma terminológica normalização nas línguas técnicas é própria da adopção de políticas linguísticas articuladas sobre a crença 
de que o uso recorrente de um mesmo termo garante a univocidade de comunicação especializada.

Defendemos a criação de estratégias para incentivar, promover e desenvolver a aprendizagem da língua Kimbundu, desenvolvendo metodologias integradas na era digital. Neste sentido, impõe-se o recurso a conteúdos interactivos e de trabalhos colaborativos controlados, o que pressupõe escolhas na concepção dos conteúdos.

Sendo hoje, a cultura um importante factor da sociedade humana, cada comunidade deve usar as suas línguas locais para a transmissão da sua experiência às gerações mais jovens, perpetuando, deste modo, a sua realidade sociocultural.

A UNESCO considera que todas as línguas do mundo são essenciais para a identidade da pessoa, das comunidades e para a coexistência pacífica destas, além de se constituírem como factor estratégico a fim de se registarem progressos na via do desenvolvimento sustentável, bem como, para a articulação harmoniosa entre a dimensão mundial e a local.

Também convida os Governos, os organismos das Nações Unidas, as organizações da sociedade civil, as instituições de ensino, as associações de profissionais e todas as restantes partes interessadas a desenvolverem as suas actividades a favor do respeito, da promoção e da protecção de todas as línguas, das que se encontram numa situação de risco, seja a nível individual ou a nível colectivo.

Desenvolver a cultura não significa submetê-la a outras. Temos, por isso, de admitir que as aculturações resultantes do contacto cultural com os demais povos não devem resultar em perda da personalidade do angolano no contexto dos seus valores antropológicos materiais e espirituais.

Há uma necessidade urgente de resgatar os valores culturais Angolanos mediante a valorização das línguas nacionais angolanas no seio dos circuitos familiares.

Todas as comunidades linguísticas têm direito a usar a sua língua, a mantêla e a promovê-la em todas as suas formas de expressão cultural. 


\section{REFERENCIAS}

Andrade, E. d. (2007). Línguas Africanas-Breve Introdução à Fonologia e à Morfologia. Lisboa: Editora A. Santos.

Boulanger, J.-C. (2001). Convergências e Divergências entre a Lexicografia e a Terminografia. Em M. S. Lima, \& P. Ramos, Terminologia e Ensino de segunda Língua. Porto Alegre: NEC, ABECAN.

Cabré, M. T. (1993b). La Terminología: Teoría, Metodología e Aplicaciones. Barcelona: Editorial Antártida/Empúries.

Cabré, M. T. (1999a). La Terminología Hoy: Concepciones, Tendencias y Aplicaciones. La Terminología: Representación et Comunicación, Elementos para una Teoría de Base Comunicativa y otros Artículos, pp. 17-38.

ístico e Análise das Línguas (6ª ed., Vol. I). Coimbra: Coimbra Editora Limitada.

Chicuna, A. M. (2009). Tratamento Lexicográfico dos portuguesismos em kyombe

(Tese de Doutoramento). Lisboa: Universidade Nova de Lisboa-Faculdade de Ciências Sociais e Humanas.

Conceição, M. C. (1994). Socioterminologia: Uma Nova Abordagem das Terminologias. Terminologias 9-10 ( TERMIP), pp. 33-41.

Costa, A. F. (2002). Questões da Língua e das Culturas: o ensino do Português em Angola. XII Encontro da Associação das Universidades de Língua Portuguesa. Luanda: AULP.

Costa, L. (2001). Dicionário de Tétum-Português (2ª ed.). Lisboa: Edições Colibri/Instituto Camões.

Costa, R. (2005a). O Ensino da Ciência e da Tecnologia em Português: uma questão de terminologia. Actas do I Congresso Biena I- A Língua Portuguesa na CPLP. Sonhar e Realizar em Português.

ISO/FDIS-1087-1. (2000). Travaux Terminologiques-Vocabulaire-Partie1: Théorie et Application. Genève: Organisation Internacionale de Normalisation.

Isquerdo, A. N., \& Oliveira, A. M. (2001). As Ciências do Léxico: Lexicologia, Lexicografia e terminologia ( $2^{\underline{a}}$ ed.). Campo Grande: Editora da UFMS.

Krieger, M. d., \& Finatto, M. J. (2004). Introdução à Terminologia: Teoria e Prática. São Paulo: Contexto.

Kukanda, V. (1986). Notas de Introdução à Linguistica Bantu. Lubango: Departamento de Letras Modernas.

Leiria, I. (1999). Português Língua Segunda e Língua Estrangeira: Investigação e Ensino. $1 .^{\circ}$ congresso do Português Língua não-materna. Lisboa: Fórum TelecomPicoas.

Lino, M. T. (1979). Importância da Lexicologia Contrastiva. Letras soltas 1, UNL. Lino, M. T. (1989). Língua Portuguesa, Língua das Ciências e das Técnicas: Neologia Científica e Técnica e Lexicografia. Actas do Congresso Internacional A Língua Portuguesa - Que futuro? Lisboa: Sociedade da Língua Portuguesa.

Lino, M. T. (1990). Métodos Lexicológicos e Métodos Terminológicos. Colóquio Internacional de Terminologia Científica e Técnica, U.N.L. (pp. Maria Teresa Lino, Métodos Lexicológicos e Métodos Terminológicos, Comunicação apresentada no Colóquio Internacional de Terminologia Científica e Técnica, U.N.L., Fevereiro, 1990.). Lisboa: Universidade Nova de Lisboa.

Lino, M. T. (1991b). Terminologia da 1. Lexicologia e Lexicografia, 2. Terminologia e Terminolgrafia. Lisboa: Universidade Nova de Lisboa.

Lino, M. T. (1991c). Terminologia da Lexicologia e Lexicografia. Em A. P. Linguística, Tomo II. Lisboa: Associação Portuguesa de Linguística. 
Lino, M. T. (2008). Rede de Neologia e de Terminologia em Língua Portuguesa. Actas do Encontro da Associação das Universidades de Língua Portuguesa. Cabo Verde: Associação das Universidades de Língua Portuguesa AULP e Universidade de Cabo Verde.

Mingas, A. A. (2000). Interferência do Kimbundu no Português falado em Lwanda. Luanda: Edições Chá de Caxinde.

Nacionais, I. d. (1980a). Histórico sobre a Criação dos Alfabetos em Línguas Nacionais. Lousã: Ed.70.

Nacionais, I. d. (1980b). Léxico Temático de Saúde Português/Kimbundu. Luanda: Projecto Ang/77/009.

Ngunga, A. (2004). Introdução à Linguística Bantu. Maputo: Imprensa Universitária.

Rodriguez, J. L. (2006). A Visão Sociolinguística e Antropológicas das Línguas em Luis Polanah. Babilónia. Revista Lusófona de Línguas, Culturas e Tradução. N. 004.

Rondeau, G. (1984). Introduction à la Terminologie. Paris: Gaëtan Morin éditeur. Tavares, C. F. (2007). Didáctica do Português - Língua Materna e Não Materna No Ensino Básico. Porto: Porto Editora.

Vilela, M. (1979). Estruturas Léxicas do Português. Coimbra: Livraria Almedina. Vilela, M. (1994). Estudos de Lexicologia do Português. Coimbra: Livraria Almedina. 